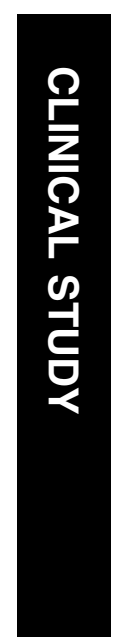

${ }^{1}$ Department of Ophthalmology, Centre for Eye Research Australia, University of Melbourne, East Melbourne, Victoria, Australia

${ }^{2}$ Glaucoma Investigation and Research Unit, Royal Victorian Eye and Ear Hospital, East Melbourne, Victoria, Australia

Correspondence: JG Crowston,

Department of Ophthalmology, Centre for Eye Research Australia,

University of Melbourne, 32 Gisborne Street, Locked Bag 8, East Melbourne, Victoria 8002. Australia

Tel: + 6139929 8196; Fax: + 61399298164 .

E-mail: crowston@

unimelb.edu.au

Received: 26 May 2008 Accepted in revised form: 4 December 2008 Published online: 30 January 2009

This study was supported by the Hector Maclean Scholarship (DS) and Glaucoma Australia.

\title{
Topical prostaglandin analogues do not affect selective laser trabeculoplasty outcomes
}

\begin{abstract}
Purpose To investigate the effect of topical prostaglandin analogue use on the efficacy of selective laser trabeculoplasty (SLT)

intraocular pressure (IOP) lowering in patients with open-angle glaucoma.
\end{abstract}

Patients and Methods This retrospective study included 123 consecutive patients who underwent $180^{\circ}$ SLT for the first time. Eyes were grouped into those that received prostaglandin analogues before and after SLT $(n=74)$ and those that did not $(n=49)$. The main outcome measure was IOP lowering after SLT. Success was defined as $\geqslant \mathbf{2 0 \%}$ reduction in IOP without further glaucoma intervention. Results There was no significant difference in IOP lowering at 6 months post-laser between the prostaglandin and non-prostaglandin groups ( $3.9 \pm 4.8$ vs $4.6 \pm 3.6 \mathrm{~mm} \mathrm{Hg}, P=0.43$ ). Long-term SLT success rates were also not significantly different between the treatment groups (Kaplan-Meier survival analysis, $P=0.68$ ). IOP lowering at 6 months was similar in eyes that received no glaucoma medications, monotherapy with or without a prostaglandin analogue, or combination therapy with or without prostaglandin analogues $(P=0.81)$. Logistic regression analysis showed that various patient characteristics including age, sex, type of glaucoma, previous glaucoma surgery, and other glaucoma risk factors did not predict a successful SLT outcome. However, higher pre-operative IOP was found to predict SLT success (odds ratio $=1.12,95 \% \mathrm{CI}=1.02$ 1.24, $P=0.02$ ).

Conclusion The IOP lowering efficacy of SLT is not influenced by the use of topical prostaglandin analogues. Eye (2009) 23, 2194-2199; doi:10.1038/eye.2009.1; published online 30 January 2009
D Singh', MA Coote ${ }^{1,2}$, F O'Hare $^{1}$, MJ Walland ${ }^{2}$, S Ghosh ${ }^{1,2}$, J Xie' ${ }^{1}$, JB Ruddle ${ }^{1,2}$ and JG Crowston ${ }^{1,2}$
Keywords: glaucoma; intraocular pressure; selective laser trabeculoplasty; prostaglandin analogues

\section{Introduction}

Selective laser trabeculoplasty (SLT) is performed with a $532 \mathrm{~nm} \mathrm{Nd:YAG} \mathrm{laser,} \mathrm{and}$ targets the pigmented cells of the trabecular meshwork. ${ }^{1}$ SLT has been shown to produce similar intraocular pressure (IOP) lowering to argon laser trabeculoplasty (ALT). ${ }^{2,3}$

Histological studies suggest reduced damage to the trabecular meshwork with SLT, compared to ALT. ${ }^{4}$ However, the use of SLT as a repeatable procedure in open-angle glaucoma requires further validation.

Various clinical studies have demonstrated the efficacy and safety of SLT in producing a sustained reduction in IOP. ${ }^{1,2,5-11}$ SLT has also been shown to be effective as both primary treatment and as an adjunct to medical therapy. ${ }^{9-11}$ A proportion of patients fail to respond to SLT and the reported success rates have varied considerably between published studies. The factors responsible for this variability are unclear. The effect of topical IOPlowering medications on the efficacy of SLT has not been investigated in depth. Given their efficacy and safety, prostaglandin analogues are now routinely used to control IOP. ${ }^{12,13}$ A recent report suggested that topical prostaglandin analogue use before and after SLT is associated with a greater reduction in IOP at 1 month after SLT. ${ }^{14}$ In contrast, another study demonstrated reduced IOP lowering after SLT in eyes of patients taking prostaglandin analogues. ${ }^{15}$ The aim of this study was to further investigate the effect of topical prostaglandin analogues on SLT 
efficacy. A secondary aim was to investigate other potential predictors of SLT success.

\section{Materials and methods}

We conducted a retrospective analysis of consecutive patients treated with SLT by a single clinician, from January 2006 to June 2007. All patients with open-angle glaucoma or ocular hypertension who underwent SLT for the first time and had a minimum of 6-month follow-up were included in the study. One eye was randomly selected for those patients who had SLT in both eyes. Data were collected by medical chart review and included demographic information, lens status, glaucoma risk factors, glaucoma type, glaucoma medication history, prior glaucoma surgery, and SLT parameters.

\section{Surgical technique}

All cases of SLT were performed by an experienced glaucoma surgeon (MC) with the q-switched frequencydoubled $532 \mathrm{~nm} \mathrm{Nd:YAG} \mathrm{laser} \mathrm{(Lumenis} \mathrm{Selecta} \mathrm{700;}$ Coherent Medical Group, Santa Clara, CA, USA). The inferior $180^{\circ}$ of the distal pigmented trabecular meshwork was treated with approximately 50 continuous but non-overlapping spots. An initial power setting of $0.8 \mathrm{~W}$ was titrated against micro-bubble formation. Patients were pretreated with topical $1 \%$ pilocarpine $1 \mathrm{~h}$ before SLT and were not given topical steroids after treatment.

\section{Outcome parameters}

The primary outcome of this study was IOP lowering 6 months after SLT. To provide a baseline IOP for each eye, Goldmann applanation IOP measurements from three separate pre-laser visits occurring over 3 months were recorded and averaged. Post-laser IOP was recorded at the follow-up visit occurring closest to 3 and 6 months. A 'successful' SLT outcome was defined as a reduction in IOP of $20 \%$ or more compared to baseline, without the need for additional glaucoma intervention (further SLT, trabeculectomy surgery, or addition of a glaucoma medication). Cases were regarded as unsuccessful if they underwent further glaucoma intervention at any time during follow-up. We chose this definition of success because it is the most commonly used in the SLT literature. $5,2,7,10,11,16$

To analyse the effect of prostaglandin analogues on SLT efficacy, we categorized eyes according to whether they received a topical prostaglandin analogue (bimatoprost, latanoprost, or travoprost) as part of their glaucoma medical therapy before laser and during the follow-up period. The eyes that did not receive prostaglandins included those not receiving any topical medications and eyes treated with other topical agents ( $\beta$-blockers, $\alpha$ - 2 agonists, or carbonic anhydrase inhibitors). Patients who were prescribed glaucoma medications for less than 3 months before SLT or those who had glaucoma medications discontinued or altered during the course of follow-up were excluded from this study. Medications were altered in these patients due to either side effects, a lack of clinical response, or patient preference. In a separate analysis, we also compared successful and non-successful SLT treatments, independent of topical medication use, to investigate possible patient and ocular factors that may predict SLT success.

\section{Statistical analysis}

Statistical analysis was performed with the GraphPad Prism Software for Windows and SPSS 16.0 statistical software package (SPSS Inc., Chicago, IL, USA).

Statistical significance in the differences between groups (defined as $P<0.05$ ) was detected with the Student's $t$-test or one-way analysis of variance for continuous variables and with the $\chi^{2}$-test or Fisher's exact test for categorical variables. Success rates between groups were compared with Kaplan-Meier survival analysis and logrank (Mantel-Cox) tests. Association between SLT outcome and various patient characteristics, including age, sex, type of glaucoma, previous glaucoma surgery, and other glaucoma risk factors was assessed by logistic regression. Odds ratios (OR) with $95 \%$ confidence intervals $(\mathrm{CI})$ were given to estimate the relative risk.

We certify that all applicable institutional and governmental regulations concerning the ethical use of human volunteers were followed during this research.

\section{Results}

A total of 123 eyes were identified during the study period of which 74 eyes received prostaglandin analogues before and after SLT and 49 eyes received either other non-prostaglandin agents or no medications. The distribution of topical medication use in each treatment group is presented in Table 1. The treatment groups were similar in terms of demographics and baseline characteristics (Table 1).

The mean baseline IOP ( \pm SD) was $20.9 \pm 4.5$ in the prostaglandin group and $19.8 \pm 4.3 \mathrm{~mm} \mathrm{Hg}$ in the nonprostaglandin group (Figure 1). There was no statistical difference in mean IOP between each treatment group at baseline $(P=0.20)$, at 3 months, $(P=0.54)$, or 6 months after SLT ( $P=0.72$, unpaired $t$-test). At the last follow-up period, the reduction in IOP from baseline was also 
Table 1 Comparison of baseline characteristics of the prostaglandin and non-prostaglandin groups

\begin{tabular}{|c|c|c|c|}
\hline Characteristic & Prostaglandin $(\mathrm{n}=74)$ & Non-prostaglandin $(\mathrm{n}=49)$ & P-value \\
\hline Age (mean $\pm S D$, years) & $64.9 \pm 12.2$ & $67.9 \pm 11.8$ & $0.17^{\mathrm{a}}$ \\
\hline Sex (male/female) & $41 / 33$ & $23 / 26$ & $0.46^{\mathrm{b}}$ \\
\hline \multicolumn{4}{|l|}{ Medications, $\mathrm{n}$} \\
\hline Prostaglandin analogue & 74 & 0 & \\
\hline$\beta$-Antagonist & 15 & 13 & \\
\hline$\alpha$-Agonist & 11 & 7 & \\
\hline Carbonic anhydrase inhibitor & 8 & 3 & \\
\hline Nil & 0 & 34 & \\
\hline \multicolumn{4}{|l|}{ Risk factors (Yes/No) } \\
\hline Positive family history & $17 / 57$ & $8 / 41$ & $0.49^{\mathrm{b}}$ \\
\hline Hypertension & $23 / 51$ & $12 / 37$ & $0.54^{\mathrm{b}}$ \\
\hline Diabetes mellitus & $6 / 68$ & $4 / 45$ & $0.99^{\mathrm{b}}$ \\
\hline Myopia & $11 / 63$ & $10 / 39$ & $0.47^{\mathrm{b}}$ \\
\hline Lens status (phakic/pseudophakic) & $51 / 23$ & $29 / 20$ & $0.33^{\mathrm{b}}$ \\
\hline BCVA $(\log M A R \pm S D)$ & $0.16 \pm 0.49$ & $0.075 \pm 0.35$ & $0.26^{\mathrm{a}}$ \\
\hline \multicolumn{4}{|l|}{ Glaucoma diagnosis $\mathrm{n},(\%)$} \\
\hline POAG & $52(70)$ & $31(63)$ & $0.42^{\mathrm{c}, \mathrm{d}}$ \\
\hline OHTN & $9(12)$ & $6(12)$ & \\
\hline PXF & $4(5)$ & $6(12)$ & \\
\hline PDG & $6(8)$ & $5(10)$ & \\
\hline Other & $3(4)$ & $1(2)$ & \\
\hline \multicolumn{4}{|l|}{ Previous glaucoma treatment (Yes/No) } \\
\hline ALT & $5 / 69$ & 0 & \\
\hline Trabeculectomy & $2 / 72$ & 0 & \\
\hline YAG peripheral iridotomy & $6 / 68$ & $5 / 44$ & $0.75^{\mathrm{b}}$ \\
\hline Total energy during SLT (mean $\pm \mathrm{SD}, \mathrm{mJ})$ & $53.9 \pm 14.5$ & $54.9 \pm 15.7$ & $0.74^{\mathrm{a}}$ \\
\hline
\end{tabular}

Abbreviations: ALT, argon laser trabeculoplasty; BCVA, best-corrected visual acuity; IOP, intraocular pressure; logMAR, logarithmic minimum angle of resolution; OHTN ocular hypertension; PDG, pigment dispersion glaucoma; POAG, primary open-angle glaucoma; PXF, pseudoexfoliation glaucoma; $\mathrm{SD}$, standard deviation.

aUnpaired $t$-test.

${ }^{\text {b} F i s h e r ' s ~ e x a c t ~ t e s t . ~}$

${ }^{c} \chi^{2}$-Test.

${ }^{\mathrm{d} P O A G}$ compared to all other glaucoma diagnoses.

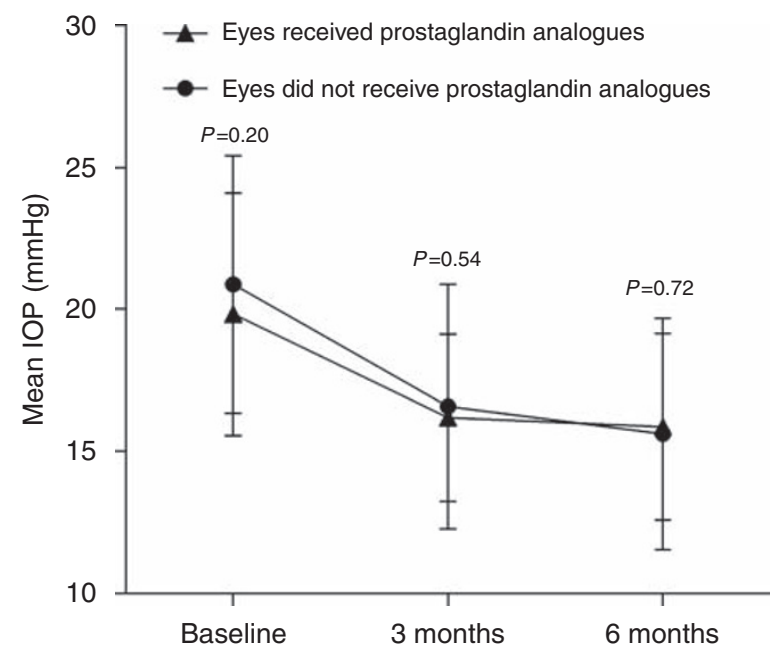

Figure 1 Intraocular pressure (IOP) profile before and after selective laser trabeculoplasty. Values are mean \pm standard deviation. $P$-values are for unpaired $t$-test.

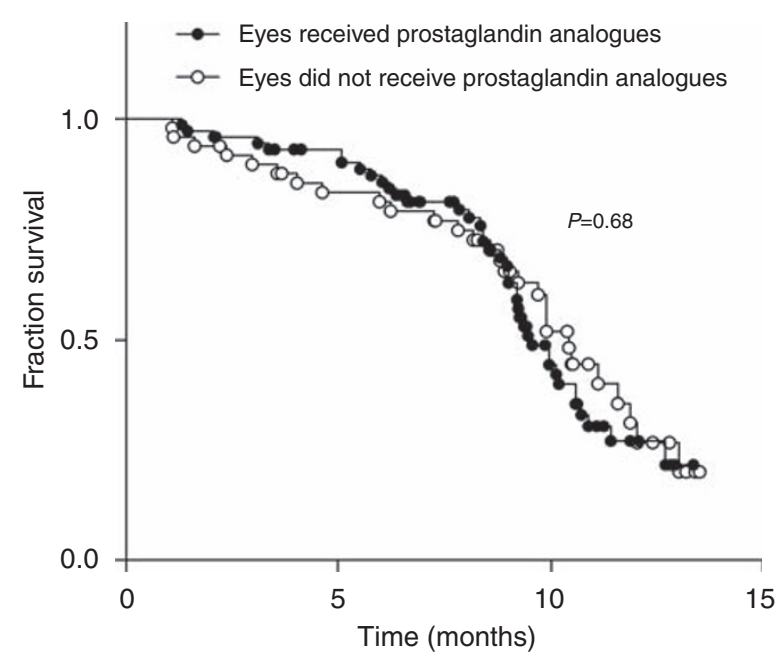

Figure 2 Kaplan-Meier survival curves for selective laser trabeculoplasty success, defined as a reduction in intraocular pressure of at least $20 \%$ without further glaucoma intervention. 
similar between treatment groups, with IOP decreasing by a mean of $3.9 \pm 4.8 \mathrm{~mm} \mathrm{Hg}$ in the prostaglandin group and $4.6 \pm 3.6 \mathrm{~mm} \mathrm{Hg}$ in the non-prostaglandin group $(P=0.43$, unpaired $t$-test $)$. We estimated the power of this study to detect a clinically relevant difference of $2 \mathrm{~mm} \mathrm{Hg}$ in mean IOP between the two treatment groups was $80 \%$ ( $\alpha=0.05$, two tailed).

A total of 29 eyes (39\%) in the prostaglandin group and 22 eyes $(45 \%)$ in the non-prostaglandin group met SLT success criteria ( $\geqslant 20 \%$ reduction in IOP at last follow-up without further glaucoma interventions). Kaplan-Meier survival analysis, using this definition of SLT success, showed no significant difference between treatment groups (Figure 2, log-rank $P=0.68$ ).
In a subgroup analysis, IOP lowering at 6 months was similar in eyes that received no glaucoma medications, monotherapy with or without a prostaglandin analogue, or combination therapy with or without prostaglandin analogues (Table $2, P=0.81$, one-way analysis of variance).

To investigate whether certain demographic characteristics, glaucoma risk factors, previous ALT or glaucoma surgery, or lens status predicted SLT success in this patient sample, we compared the distribution of these variables between the success and non-success groups (Table 3 ). Analysis by multivariable logistic regression found a higher baseline IOP to be a predictor of SLT success (Table 3), however other factors did not correlate with SLT outcome.

Table 2 Intraocular pressure following selective laser trabeculoplasty in eyes receiving nil, single, or multiple topical glaucoma medications

\begin{tabular}{lcccccc}
\hline Time & $\begin{array}{c}\text { No topical } \\
\text { medications } \\
(\mathrm{n}=34)\end{array}$ & $\begin{array}{c}\text { Non-prostaglandin } \\
\text { monotherapy } \\
(\mathrm{n}=8)\end{array}$ & $\begin{array}{c}\text { Non-prostaglandin } \\
\text { combination } \\
\text { therapy }(\mathrm{n}=7)\end{array}$ & $\begin{array}{c}\text { Prostaglandin } \\
\text { monotherapy } \\
(\mathrm{n}=45)\end{array}$ & $\begin{array}{c}\text { Prostaglandin } \\
\text { combination } \\
\text { therapy }(\mathrm{n}=29)\end{array}$ & $\begin{array}{c}\text { P-values } \\
{ }^{\mathrm{a}}\end{array}$ \\
\hline Baseline & $20.2 \pm 4.3$ & $19.57 \pm 3.8$ & $20.2 \pm 5.8$ & $19.2 \pm 3.7$ & $20.9 \pm 4.9$ & 0.57 \\
3 months post-SLT & $17.1 \pm 4.4$ & $16.6 \pm 4.7$ & $14.3 \pm 3.0$ & $16.0 \pm 3.2$ & $16.4 \pm 2.5$ & 0.39 \\
6 months post-SLT & $16.2 \pm 4.0$ & $14.2 \pm 1.9$ & $15.6 \pm 4.5$ & $15.1 \pm 3.2$ & $16.6 \pm 3.7$ & 0.32 \\
IOP lowering at 6 & $4.3 \pm 3.3$ & $6.2 \pm 3.4$ & $4.7 \pm 4.8$ & $3.9 \pm 3.9$ & $4.0 \pm 5.9$ & 0.81 \\
months & & & & &
\end{tabular}

Abbreviations: IOP, intraocular pressure; SD, standard deviation; SLT, selective laser trabeculoplasty.

${ }^{a}$ One-way analysis of variance; values are expressed as mean $\pm \mathrm{SD}, \mathrm{mm} \mathrm{Hg}$.

Table 3 Logistic regression analysis of baseline characteristics and glaucoma risk factors in successful and non-successful eyes

\begin{tabular}{|c|c|c|c|c|c|c|}
\hline \multirow[t]{2}{*}{ Characteristic } & \multirow{2}{*}{$\begin{array}{c}\text { SLT } \\
\text { successful } \\
(\mathrm{n}=51)\end{array}$} & \multirow{2}{*}{$\begin{array}{c}\text { SLT not } \\
\text { successful } \\
(\mathrm{n}=72)\end{array}$} & \multicolumn{2}{|c|}{ Unadjusted } & \multicolumn{2}{|c|}{ Adjusted } \\
\hline & & & OR $(95 \% C I)$ & P-value & OR $(95 \% \mathrm{CI})$ & P-value \\
\hline Age (mean $\pm S D$, years) & $65.4 \pm 11.8$ & $67.7 \pm 12.2$ & $0.98(0.95,1.01)$ & 0.29 & $1.00(0.97,1.04)$ & 0.90 \\
\hline Sex (male/female) & $26 / 25$ & $38 / 34$ & $0.93(0.45,1.91)$ & 0.84 & $0.89(0.40,2.02)$ & 0.80 \\
\hline \multicolumn{7}{|l|}{ Risk factors (Yes/No) } \\
\hline Positive family history & $9 / 42$ & $16 / 56$ & $0.75(0.30,1.860)$ & 0.54 & $0.81(0.30,2.20)$ & 0.69 \\
\hline Hypertension & $12 / 39$ & $23 / 49$ & $0.65(0.29,1.48)$ & 0.31 & $0.79(0.31,2.07)$ & 0.63 \\
\hline Diabetes mellitus & $2 / 49$ & $8 / 64$ & $0.33(0.07,1.61)$ & 0.17 & $0.34(0.06,2.10)$ & 0.25 \\
\hline Myopia & $7 / 44$ & $14 / 58$ & $0.66(0.25,1.77)$ & 0.41 & $0.48(0.16,1.51)$ & 0.21 \\
\hline Lens (phakic/pseudophakic) & $38 / 13$ & $42 / 30$ & $2.08(0.94,4.57)$ & 0.07 & $1.91(0.76 .4 .86)$ & 0.17 \\
\hline BCVA $(\log M A R \pm S D)$ & $0.02 \pm 0.19$ & $0.05 \pm 0.25$ & $0.50(0.09,2.07)$ & 0.42 & $0.52(0.07,3.89)$ & 0.53 \\
\hline Glaucoma diagnosis (POAG/other types) & $32 / 19$ & $51 / 21$ & $0.69(0.32,1.49)$ & 0.35 & $0.83(0.35,1.97)$ & 0.68 \\
\hline \multicolumn{7}{|l|}{ Previous glaucoma surgery (Yes/No) } \\
\hline ALT & $2 / 49$ & $3 / 69$ & $0.94(0.15,5.83)$ & 0.94 & $0.99(0.14,7.20)$ & 0.99 \\
\hline YAG peripheral iridotomy & $4 / 47$ & $7 / 65$ & $0.79(0.22,2.85)$ & 0.72 & $0.74(0.18,2.93)$ & 0.66 \\
\hline Baseline IOP (mean $\pm \mathrm{SD}, \mathrm{mm} \mathrm{Hg}$ ) & $21.3 \pm 3.6$ & $19.5 \pm 4.7$ & $1.10(1.01,1.20)$ & 0.029 & $1.12(1.02,1.24)$ & 0.02 \\
\hline
\end{tabular}

Abbreviations: ALT, argon laser trabeculoplasty; BCVA, best-corrected visual acuity; CI, confidence interval; IOP, intraocular pressure; logMAR, logarithmic minimum angle of resolution; OHTN, ocular hypertension; OR, odds ratio; POAG, primary open-angle glaucoma; SD, standard deviation; SLT, selective laser trabeculoplasty.

Success was defined as $\geqslant 20 \%$ IOP reduction from baseline to last follow-up after SLT without further glaucoma interventions. 


\section{Conclusion}

The value of IOP lowering in slowing glaucoma progression as determined by either visual field loss or change in optic nerve head and retinal nerve fibre layer morphology has been established by various large prospective randomized studies. ${ }^{17-20}$ SLT is a relatively new treatment available to lower IOP in glaucoma but the factors that influence its efficacy remain to be elucidated. As a primary therapy for open-angle glaucoma or ocular hypertension, SLT and medical therapy with prostaglandin analogues have shown similar efficacy.,11 Prostaglandin analogues are now the first choice for topical medical therapy in many glaucoma patients. We investigated possible synergism between SLT and prostaglandin analogues in reducing IOP in patients with open-angle glaucoma.

This study found that the reduction in IOP following SLT and success rate was similar in eyes receiving topical prostaglandin analogues before and after SLT (in combination with other non-prostaglandin agents) compared to eyes that received either no glaucoma medications or other non-prostaglandin agents.

Furthermore, SLT efficacy was found to be similar in eyes receiving no topical medications, single medications, or multiple medications. There was a minor difference between the treatment groups in terms of previous ALT or trabeculectomy (Table 3). However when the small group of patients in the prostaglandin group who had received previous glaucoma surgery or ALT was excluded, no significant difference in IOP lowering was observed.

Given the retrospective nature of this study, it was not possible to use a predetermined protocol for administering medications during the follow-up period. In an effort to remove this confounding variable, we excluded eyes that had medications altered during follow-up. Although this may introduce a selection bias into the study, the excluded cases were quite similar to the rest of the study population in terms of baseline IOP and other demographic characteristics.

Our findings differ to a recent study by Scherer, ${ }^{14}$ who found eyes treated with prostaglandin analogues before and after $180^{\circ}$ SLT had a greater reduction in IOP and a higher success rate at 30 days after treatment (defined by the same criteria as our study) than eyes receiving nonprostaglandin medications. Interestingly, this earlier study reported an unusually small reduction in IOP in eyes treated with non-prostaglandin medications, ${ }^{14}$ whereas results in prostaglandin-treated eyes are quite similar to our findings. Elsewhere, in a retrospective review, prostaglandin use was associated with a higher, but statistically non-significant rate of SLT failure (defined as those patients not achieving a $20 \%$ reduction in IOP after $180^{\circ}$ laser treatment). ${ }^{15}$

SLT outcomes vary considerably in published literature, where reports of IOP reduction range from 12 to $30 \%$ of baseline and success rates range from 20 to $96 \%$, depending on the definition of success. ${ }^{5,1,2,6-11,15}$ The mean reduction in IOP and success rate observed in our study is lower than a number of other studies. ${ }^{1,2,9-11}$ This difference may be explained by the lower baseline IOP in our patient cohort. Indeed, we found a higher baseline IOP to be a significant predictor of success following SLT, which is consistent with a number of other reports. $5,7,15$ Our study also differs from the majority of prior studies in the use of three separate baseline IOP measurements to reduce influence from regression to the mean.

Analysis of patient characteristics and glaucoma risk factors showed that age, sex, family history of glaucoma, diabetes mellitus, hypertension, pseudophakia, myopia, type of glaucoma, and previous treatment for glaucoma did not predict a successful SLT outcome. This is in agreement with a number of other studies. 5,15

In conclusion, this study presents data showing that the long-term efficacy of SLT in terms of IOP reduction is not influenced by treatment with topical prostaglandin analogues.

\section{References}

1 Latina MA, Sibayan SA, Shin DH, Noecker RJ, Marcellino G. Q-switched 532-nm Nd:YAG laser trabeculoplasty (selective laser trabeculoplasty): a multicenter, pilot, clinical study. Ophthalmology 1998; 105: 2082-2088; discussion 2089-2090.

2 Damji KF, Bovell AM, Hodge WG, Rock W, Shah K, Buhrmann $\mathrm{R}$ et al. Selective laser trabeculoplasty vs argon laser trabeculoplasty: results from a 1-year randomised clinical trial. Br J Ophthalmol 2006; 90: 1490-1494.

3 Martinez-de-la-Casa JM, Garcia-Feijoo J, Castillo A, Matilla M, Macias JM, Benitez-del-Castillo JM et al. Selective vs argon laser trabeculoplasty: hypotensive efficacy, anterior chamber inflammation, and postoperative pain. Eye 2004; 18: $498-502$.

4 Kramer TR, Noecker RJ. Comparison of the morphologic changes after selective laser trabeculoplasty and argon laser trabeculoplasty in human eye bank eyes. Ophthalmology 2001; 108: 773-779.

5 Hodge WG, Damji KF, Rock W, Buhrmann R, Bovell AM, Pan Y. Baseline IOP predicts selective laser trabeculoplasty success at 1 year post-treatment: results from a randomised clinical trial. Br J Ophthalmol 2005; 89: 1157-1160.

6 Francis BA, Ianchulev T, Schofield JK, Minckler DS. Selective laser trabeculoplasty as a replacement for medical therapy in open-angle glaucoma. Am J Ophthalmol 2005; 140: 524-525.

7 Johnson PB, Katz LJ, Rhee DJ. Selective laser trabeculoplasty: predictive value of early intraocular 
pressure measurements for success at 3 months. $\mathrm{Br} J$ Ophthalmol 2006; 90: 741-743.

8 Juzych MS, Chopra V, Banitt MR, Hughes BA, Kim C, Goulas MT et al. Comparison of long-term outcomes of selective laser trabeculoplasty $v$ s argon laser trabeculoplasty in open-angle glaucoma. Ophthalmology 2004; 111: 1853-1859.

9 McIlraith I, Strasfeld M, Colev G, Hutnik CM. Selective laser trabeculoplasty as initial and adjunctive treatment for openangle glaucoma. J Glaucoma 2006; 15: 124-130.

10 Melamed S, Ben Simon GJ, Levkovitch-Verbin H. Selective laser trabeculoplasty as primary treatment for open-angle glaucoma: a prospective, nonrandomized pilot study. Arch Ophthalmol 2003; 121: 957-960.

11 Nagar M, Ogunyomade A, O'Brart DP, Howes F, Marshall J. A randomised, prospective study comparing selective laser trabeculoplasty with latanoprost for the control of intraocular pressure in ocular hypertension and open angle glaucoma. Br J Ophthalmol 2005; 89: 1413-1417.

12 Camras CB, Alm A, Watson P, Stjernschantz J. Latanoprost, a prostaglandin analog, for glaucoma therapy. Efficacy and safety after 1 year of treatment in 198 patients. Latanoprost Study Groups. Ophthalmology 1996; 103: 1916-1924.

13 Higginbotham EJ, Schuman JS, Goldberg I, Gross RL, VanDenburgh AM, Chen K et al. One-year, randomized study comparing bimatoprost and timolol in glaucoma and ocular hypertension. Arch Ophthalmol 2002; 120: 1286-1293.
14 Scherer WJ. Effect of topical prostaglandin analog use on outcome following selective laser trabeculoplasty. J Ocul Pharmacol Ther 2007; 23: 503-512.

15 Song J, Lee PP, Epstein DL, Stinnett SS, Herndon Jr LW, Asrani SG et al. High failure rate associated with 180 degrees selective laser trabeculoplasty. I Glaucoma 2005; 14: 400-408.

16 Gracner T. Intraocular pressure response to selective laser trabeculoplasty in the treatment of primary open-angle glaucoma. Ophthalmologica 2001; 215: 267-270.

17 The AGIS Investigators. The Advanced Glaucoma Intervention Study (AGIS): 7. The relationship between control of intraocular pressure and visual field deterioration. Am J Ophthalmol 2000; 130: 429-440.

18 Heijl A, Leske MC, Bengtsson B, Hyman L, Bengtsson B, Hussein M. Reduction of intraocular pressure and glaucoma progression: results from the Early Manifest Glaucoma Trial. Arch Ophthalmol 2002; 120: 1268-1279.

19 Kass MA, Heuer DK, Higginbotham EJ, Johnson CA, Keltner JL, Miller JP et al. The Ocular Hypertension Treatment Study: a randomized trial determines that topical ocular hypotensive medication delays or prevents the onset of primary open-angle glaucoma. Arch Ophthalmol 2002; 120: 701-713; discussion 829-730.

20 Lichter PR, Musch DC, Gillespie BW, Guire KE, Janz NK, Wren PA et al. Interim clinical outcomes in the Collaborative Initial Glaucoma Treatment Study comparing initial treatment randomized to medications or surgery. Ophthalmology 2001; 108: 1943-1953. 